\begin{tabular}{|c|c|c|}
\hline Yumiko Tsushima, MD & M. Cecilia Lansang, MD, MPH & Vinni Makin, MBBS, MD, FACE \\
\hline $\begin{array}{l}\text { Department of Endocrinology, Diabetes, } \\
\text { and Metabolism, Cleveland Clinic }\end{array}$ & $\begin{array}{l}\text { Director, Main Campus Department of } \\
\text { Endocrinology, Department of Endocrinology, } \\
\text { Diabetes, and Metabolism, Cleveland Clinic; } \\
\text { Professor of Medicine, Cleveland Clinic Lerner } \\
\text { College of Medicine of Case Western Reserve } \\
\text { University, Cleveland, OH }\end{array}$ & $\begin{array}{l}\text { Director, East Region, Department of Endocri- } \\
\text { nology Diabetes, and Metabolism, Cleveland } \\
\text { Clinic; Assistant Professor of Medicine, Cleve- } \\
\text { land Clinic Lerner College of Medicine of Case } \\
\text { Western Reserve University, Cleveland, OH }\end{array}$ \\
\hline
\end{tabular}

\title{
The role of SGLT-2 inhibitors in managing type 2 diabetes
}

\section{ABSTRACT}

Sodium-glucose cotransporter-2 (SGLT-2) inhibitors are an exceptionally versatile class of medication, and their glycemic and nonglycemic benefits could help millions of patients with type 2 diabetes. Of note, they have been shown to improve cardiac and renal outcomes, muchneeded benefits in patients with type 2 diabetes, who are at a higher risk for developing cardiac and renal dysfunction than those who do not have diabetes. The indications for SGLT-2 inhibitors may continue to expand as ongoing clinical trials provide more insight into these drugs.

\section{KEY POINTS}

SGLT-2 inhibitors improve glycemic control, reduce hospitalizations for heart failure, and slow the progression of renal disease.

Consider an SGLT-2 inhibitor as first- or second-line therapy (after metformin) in patients with type 2 diabetes with cardiovascular disease or renal disease, or both, regardless of glycemic control.

Consider an SGLT-2 inhibitor in overweight or obese patients with type 2 diabetes.

Be aware of the possibility of genital infections and diabetic ketoacidosis with SGLT-2 inhibitor use.
$\mathrm{O}$ PTIONS FOR TREATING type 2 diabetes mellitus have expanded with the introduction of the sodium-glucose cotransporter-2 (SGLT-2) inhibitors and glucagon-like protein-1 (GLP-1) receptor agonists. These drugs improve glycemic control and possess cardiovascular and metabolic benefits.

See related editorial, page 59

This article will discuss and interpret recent studies regarding the benefits of SGLT-2 inhibitors and their role in the treatment of type 2 diabetes. By doing so, we aim to provide guidance for clinicians, particularly primary care physicians and general internists, in their decision-making in managing type 2 diabetes.

\section{SODIUM-GLUCOSE COTRANSPORTER-2}

The kidneys play a role in regulating blood glucose levels by filtering out glucose in the glomerulus and then reabsorbing it in the proximal tubule. They can filter and reabsorb approximately $180 \mathrm{~g}$ of glucose per day, and less than $1 \%$ is excreted into the urine. ${ }^{1,2}$ The transporters responsible for reabsorbing glucose from the tubular lumen into the blood stream are the sodium-glucose cotransporters 1 and 2 (SGLT-1 and SGLT-2, respectively). SGLT-1 is located in the distal segment of the proximal tubule and reabsorbs approximately $10 \%$ of the glucose that is filtered by the glomerulus, while SGLT-2 is located in the proximal portion of the proximal tubule and reabsorbs about $90 \% .^{3}$

In type 2 diabetes, expression of SGLT2 is increased, which increases the ability of the kidneys to reabsorb glucose. ${ }^{3}$ This in turn causes glucose to not spill into the urine un- 
TABLE 1 Absolute change in hemoglobin $A_{1 c}$ with SGLT-2 inhibitor monotherapy
compared with placebo

\begin{tabular}{|c|c|c|c|c|c|c|c|}
\hline \multicolumn{2}{|c|}{ Empagliflozina } & \multicolumn{2}{|c|}{ Canagliflozin ${ }^{b}$} & \multicolumn{2}{|c|}{ Dapagliflozinc } & \multicolumn{2}{|c|}{ Ertugloflozin $^{d}$} \\
\hline $\begin{array}{l}\text { Low } \\
\text { dose }\end{array}$ & $\begin{array}{l}\text { High } \\
\text { dose }\end{array}$ & $\begin{array}{l}\text { Low } \\
\text { dose }\end{array}$ & $\begin{array}{l}\text { High } \\
\text { dose }\end{array}$ & $\begin{array}{l}\text { Low } \\
\text { dose }\end{array}$ & $\begin{array}{l}\text { High } \\
\text { dose }\end{array}$ & $\begin{array}{l}\text { Low } \\
\text { dose }\end{array}$ & $\begin{array}{l}\text { High } \\
\text { dose }\end{array}$ \\
\hline$-0.74 \%$ & $-0.85 \%$ & $-0.90 \%$ & $-1.20 \%$ & $-0.54 \%$ & $-0.60 \%$ & $-0.50 \%$ & $-0.50 \%$ \\
\hline
\end{tabular}

til the plasma glucose level reaches about 220 $\mathrm{mg} / \mathrm{dL}$, instead of the usual threshold of about $180 \mathrm{mg} / \mathrm{dL}$. Conversely, drugs that inhibit SGLT-2 promote glycosuria in exchange for lower plasma glucose. An advantage of these drugs is that their mechanism of action is independent of insulin secretion, beta-cell function, and insulin resistance. ${ }^{4}$

\section{EFFECT ON GLYCEMIC CONTROL}

Currently, there are 4 approved SGLT-2 inhibitors on the market: empagliflozin, canagliflozin, dapagliflozin, and ertugliflozin. No head-to-head trials have compared glycemic control with the individual drugs within the class, but in placebo-controlled trials, SGLT2 inhibitors lowered hemoglobin $A_{1 c}$ by 0.6 to 1.2 percentage points when used as monotherapy (Table 1 ), ${ }^{5-8}$ by 0.5 to 0.9 percentage points when added to metformin therapy, ${ }^{4,9-11}$ and by 0.4 to 0.6 percentage points when added to insulin and other oral antihyperglycemic agents. ${ }^{12-14}$

Because SGLT-2 inhibitors lower glucose independently of insulin, hypoglycemia is rare when they are used as monotherapy or in conjunction with noninsulin secretagogue oral agents. ${ }^{4-7,9,10}$ The incidence of hypoglycemia increases with the use of insulin or insulin secretagogues such as sulfonylureas, but severe hypoglycemic episodes remain uncommon. ${ }^{12-14}$

Nevertheless, when SGLT-2 inhibitors are used in combination with insulin or insulin secretagogues, one should consider reducing the dose of insulin or insulin secretagogue to prevent hypoglycemia:

- For patients using basal insulin, some suggest decreasing the basal insulin dose by $20 \%$ if the fasting plasma glucose level is less than $106 \mathrm{mg} / \mathrm{dL}$ and decreasing it by $10 \%$ if the fasting plasma glucose level is between 106 and $145 \mathrm{mg} / \mathrm{dL}$

- For patients using bolus insulin, consider reducing the dose by $20 \%$ if the blood glucose level is less than $106 \mathrm{mg} / \mathrm{dL}$ before meals, and by $10 \%$ if it is between 106 and $145 \mathrm{mg} / \mathrm{dL}$

- For patients using both insulin and an insulin secretagogue, consider reducing the dose of insulin secretagogue or discontinuing it altogether, particularly if blood glucose levels are less than $106 \mathrm{mg} / \mathrm{dL}$ before starting the SGLT-2 inhibitor. ${ }^{15}$

\section{EFFECT ON CARDIOVASCULAR OUTCOMES}

Approximately one-third of patients with type 2 diabetes have cardiovascular disease: about 20\% have coronary artery disease and $15 \%$ have heart failure. ${ }^{16}$ Patients with type 2 diabetes who also have heart failure have worse quality of life and a poorer prognosis. ${ }^{17,18}$ Cardiovascular disease is responsible for half of the deaths in this patient population, ${ }^{16}$ and those with type 2 diabetes who develop heart failure have a 9 to 12 times greater mortality risk than those who do not. ${ }^{19,20}$ Therefore, the ability of SGLT-2 inhibitors to reduce cardiovascular deaths and hospitalizations for heart failure is crucial in managing this population.

Four large randomized clinical trials (Table $2)^{21-24}$ have provided insight into the effects 
TABLE 2

Cardiovascular outcomes in 4 major trials of SGLT-2 inhibitors

\begin{tabular}{|c|c|c|c|c|}
\hline & $\begin{array}{l}\text { EMPA-REG } \\
\text { OUTCOME }^{21}\end{array}$ & CANVAS $^{22}$ & DECLARE-TIMI $58^{23}$ & VERTIS-CV ${ }^{24}$ \\
\hline Population & $\begin{array}{l}\text { Type } 2 \text { diabetes + } \\
\text { cardiovascular } \\
\text { disease }\end{array}$ & $\begin{array}{l}\text { Type } 2 \text { diabetes + } \\
\text { cardiovascular } \\
\text { disease or multiple } \\
\text { risk factors for it }\end{array}$ & $\begin{array}{l}\text { Type } 2 \text { diabetes + } \\
\text { cardiovascular } \\
\text { disease or multiple risk } \\
\text { factors for it }\end{array}$ & $\begin{array}{l}\text { Type } 2 \text { diabetes + } \\
\text { cardiovascular } \\
\text { disease }\end{array}$ \\
\hline Number of patients & 7,020 & 10,142 & 17,160 & 8,246 \\
\hline $\begin{array}{l}\text { History of } \\
\text { cardiovascular disease }\end{array}$ & $99 \%$ & $65.6 \%$ & $40.6 \%$ & $100 \%$ \\
\hline History of heart failure & $10.1 \%$ & $14.4 \%$ & $10.2 \%$ & $23.7 \%$ \\
\hline \multicolumn{5}{|c|}{ Outcomes with SGLT-2 inhibitor } \\
\hline $\begin{array}{l}\text { MACE } \\
\text { (relative risk reduction) }\end{array}$ & $14 \%$ & $14 \%$ & Not significant & Not significant \\
\hline $\begin{array}{l}\text { MACE } \\
\text { (number needed to treat) }\end{array}$ & 63 & 217 & Not available & Not available \\
\hline $\begin{array}{l}\text { Cardiovascular death } \\
\text { (relative risk reduction) }\end{array}$ & $38 \%$ & Not significant & Not significant & Not significant \\
\hline $\begin{array}{l}\text { Hospitalization } \\
\text { for heart failure } \\
\text { (relative risk reduction) }\end{array}$ & $35 \%$ & $33 \%$ & $27 \%$ & $30 \%$ \\
\hline $\begin{array}{l}\text { Hospitalization } \\
\text { for heart failure } \\
\text { (number needed to treat) }\end{array}$ & 71 & 312 & 125 & 91 \\
\hline
\end{tabular}

CANVAS = Canagliflozin Cardiovascular Assessment Study; DECLARE-TIMI 58 = Dapagliflozin Effect on Cardiovascular Events; EMPA-REG OUTCOME = Empagliflozin Cardiovascular Outcome Event Trial in Type 2 Diabetes Mellitus Patients; MACE = major atherosclerotic cardiovascular events; VERTIS CV = Evaluation of Ertugliflozin Efficacy and Safety Cardiovascular Outcomes

of SGLT-2 inhibitors on cardiovascular outcomes in patients with type 2 diabetes.

EMPA-REG OUTCOME (the Empagliflozin Cardiovascular Outcome Event Trial in Type 2 Diabetes Mellitus Patients) ${ }^{21}$ found that empagliflozin reduced the incidence of major atherosclerotic cardiovascular events (composite of cardiovascular death, hospitalization for heart failure, and ischemic stroke) by $14 \%$, cardiovascular death by $38 \%$, and hospitalization for heart failure by $35 \%$. There was no significant difference in efficacy between empagliflozin $10 \mathrm{mg}$ and $25 \mathrm{mg}$.

CANVAS (the Canagliflozin Cardiovascular Assessment Study) ${ }^{22}$ found that canagliflozin reduced major atherosclerotic cardio- vascular events by $14 \%$ and hospitalizations for heart failure by $33 \%$ but did not reduce cardiovascular deaths significantly.

DECLARE-TIMI 58 (the Dapagliflozin Effect on Cardiovascular Events trial) ${ }^{23}$ found that dapagliflozin did not reduce the rate of major atherosclerotic cardiovascular events, but it did reduce cardiovascular deaths by $17 \%$ and hospitalizations for heart failure by $27 \%$.

VERTIS CV (the Evaluation of Ertugliflozin Efficacy and Safety Cardiovascular Outcomes trial) ${ }^{24}$ found that ertugliflozin did not significantly reduce major atherosclerotic cardiovascular events or cardiovascular deaths, but it reduced hospitalizations for heart failure by $30 \%$. 
In summary, SGLT-2 inhibitors have been shown to have moderate benefits in terms of preventing major adverse cardiovascular events and a robust benefit in preventing hospitalizations for heart failure.

\section{A further look at heart failure}

Individually, these trials lacked the statistical power to evaluate differences in efficacy between subgroups such as those with established atherosclerotic cardiovascular disease (ASCVD) vs those with cardiovascular risk factors but without established ASCVD.

A meta-analysis ${ }^{25}$ of EMPA-REG OUTCOME, ${ }^{21}$ CANVAS, ${ }^{22}$ and DECLARE-TIMI $58^{23}$ found that in patients with established ASCVD, major atherosclerotic cardiovascular events were reduced by $14 \%$ (hazard ratio [HR] 0.86, 95\% confidence interval [CI] 0.80-0.93, $P=.0002$ ) but no treatment effect was found in the multiple cardiovascular risk factors group. The composite outcome of cardiovascular death or hospitalization for heart failure showed a $23 \%$ relative risk reduction, regardless of whether the patients had ASCVD or heart failure. When patients with and without a history of heart failure were

Approved

\section{SGLT-2}

inhibitors:

empagliflozin, canagliflozin, dapagliflozin, ertugliflozin compared, the difference in the rate of the composite outcome of cardiovascular death or hospitalizations for heart failure was not statistically significant. ${ }^{25}$

Overall, SGLT-2 inhibitors' effect on major adverse cardiac events appears to be confined to patients with established ASCVD, but their effect on reducing hospitalizations for heart failure appears to be independent of established ASCVD, risk factors, or history of heart failure.

\section{Heart failure type and the benefit of SGLT-2 inhibitors}

In view of the clear benefit of SGLT-2 inhibitors in preventing heart failure hospitalizations, a subanalysis of the DECLARE-TIMI 58 trial was undertaken to further assess this benefit in regard to heart failure phenotype (heart failure with reduced ejection fraction vs heart failure with preserved ejection fraction). ${ }^{26}$

Treatment differs for the 2 groups. For those with heart failure with reduced ejection fraction, agents such as angiotensin-converting enzyme inhibitors and beta-blockers reduce the risk of death. However, no treatments to date have been shown to lower the mortality rate in heart failure with preserved ejection fraction, and the guidelines are limited to recommending treatment of any underlying comorbidities such as hypertension, atrial fibrillation, coronary artery disease, and diabetes. ${ }^{27}$ The answer to whether SGLT-2 inhibitors benefit both types of heart failure will have an enormous impact on the future management of heart failure.

DECLARE-TIMI $58,{ }^{26}$ in a subgroup analysis, found that dapagliflozin significantly reduced hospitalizations for heart failure and cardiovascular deaths in those with heart failure with reduced ejection fraction more than in those with preserved ejection fraction or unclassified heart failure (HR 0.62 vs 0.88 , $P=.046)$. On the other hand, it appeared to reduce hospitalizations for heart failure in all patients regardless of their heart failure phenotype.

DAPA-HF (Dapagliflozin in Patients With Heart Failure and Reduced Ejection Fraction $)^{28}$ evaluated the efficacy of dapagliflozin in patients with heart failure with reduced ejection fraction regardless of diabetes diagnosis The incidence of the primary outcome (composite of worsening heart failure-unplanned hospitalization for heart failure or an urgent visit resulting in intravenous therapy for heart failure-or death from cardiovascular causes) was 26\% lower in the dapagliflozin group than in the placebo group (HR 0.74, P $<.001$ ) with a number needed to treat of 20. Hospitalizations for heart failure alone were reduced by $30 \%$. These benefits were comparable in patients with or without diabetes in the study based on a subgroup analysis. ${ }^{28}$

In May 2020, the US Food and Drug Administration (FDA) expanded the indications for dapagliflozin to include heart failure with reduced ejection fraction. ${ }^{29}$

EMPEROR-Reduced (the Empagliflozin Outcome Trial in Patients With Chronic Heart Failure With Reduced Ejection Fraction $)^{30}$ investigated the efficacy of empagliflozin in patients with heart failure with reduced ejection fraction with or without diabetes. The incidence of the primary outcome (composite of adjudicated cardiovascular death or hospitalization for heart failure) was 
$25 \%$ lower in the empagliflozin group (HR $0.75, P<.001)$ with a number needed to treat of 19. Hospitalizations for heart failure were reduced by $30 \%$. These results were similar to those of the DAPA-HF trial.

CVD REAL 2 (the Comparative Effectiveness of Cardiovascular Outcomes in New Users of SGLT-2 Inhibitors study) ${ }^{31}$ reinforced the cardiovascular benefits of SGLT-2 inhibitors. This was a large multinational observational study including cohorts from regions that were not well represented in the clinical trials mentioned above such as Asia Pacific and the Middle East. Also, the study population more closely resembled that of clinical practice in which the majority (approximately $74 \%$ ) did not have established cardiovascular disease.

Nonetheless, SGLT-2 inhibitors, compared with other glucose-lowering drugs, significantly reduced the risk of death from any cause (49\% relative risk reduction), hospitalization for heart failure (36\% reduction), composite of all-cause death and hospitalization for heart failure (40\% reduction), myocardial infarction (19\% reduction), and stroke (32\% reduction) in patients with type 2 diabetes. ${ }^{31}$ Despite differences in study population and design, the results were similar to those in previous clinical trials and were also consistent across countries.

The CVD REAL 2 study suggests that the cardiovascular benefits of SGLT-2 inhibitors may apply to a broader population of patients. $^{31}$

\section{POSSIBLE MECHANISMS OF CARDIOVASCULAR BENEFIT}

How SGLT-2 inhibitors exert their cardioprotective benefits is not fully understood, but several mechanisms have been hypothesized.

Osmotic diuresis. By increasing glycosuria and natriuresis, SGLT-2 inhibitors increase urine output and therefore decrease plasma volume and ventricular preload. ${ }^{32}$

Inhibition of the sodium-hydrogen exchanger. Cytosolic sodium concentration and sodium-hydrogen exchanger activity are both increased in the myocytes in people with diabetes and heart failure, ${ }^{33}$ and sodium-hydrogen exchanger inhibition has been shown to reduce hypertrophy in heart failure. ${ }^{34}$

Inhibition of fibrosis. Cardiac fibrosis is widely regarded as an essential factor in the development of heart failure. In a study using human cardiac fibroblasts, empagliflozin suppressed gene expression of key profibrotic markers such as type I collagen and connective tissue growth factor. ${ }^{35}$ This inhibition may lead to protection from cardiac fibrosis independent of glycemic status.

Bottom line. SGLT-2 inhibitors should be considered for all patients with type 2 diabetes who do not have contraindications to them, given their efficacy in preventing hospitalizations for heart failure in all patients regardless of ASCVD or heart failure history. They should be considered even more strongly in patients with established ASCVD. Guidelines for integrating SGLT-2 inhibitors into diabetes management are discussed further below.

\section{EFFECT ON RENAL OUTCOMES}

Another benefit of the SGLT-2 inhibitor class of medications is renal protection. Diabetes is the leading cause of kidney failure in the United States, ${ }^{36}$ and dialysis carries a poorer prognosis than some cancers. ${ }^{37}$ Furthermore, early diabetic kidney disease shortens life by 16 years compared with those without diabetes or kidney disease. ${ }^{38}$ Thus, preventing or slowing the progression of diabetic kidney disease is a key aspect of diabetes management.

CREDENCE (the Canagliflozin and Renal Events in Diabetes With Established Nephropathy Clinical Evaluation trial ${ }^{39}$ was a large, randomized, placebo-controlled, multicenter trial that assessed the effect of canagliflozin on renal outcomes in patients with type 2 diabetes and chronic kidney disease. All the participants had to have an estimated glomerular filtration rate (eGFR) of 30 to 90 $\mathrm{mL} / \mathrm{min} / 1.73 \mathrm{~m}^{2}$ and a urine albumin-to-creatinine ratio of 300 to $5,000 \mathrm{mg} / \mathrm{g}$. The primary outcome was a composite of end-stage renal disease, doubling of serum creatinine, or death from renal or cardiovascular disease.

The risk of the primary composite outcome was 30\% lower in the canagliflozin group (HR $0.70,95 \%$ CI 059-0.82, $P<.001)$. One of the secondary composite outcomes, end-stage renal disease, doubling of creatinine, or renal

\section{About one-third of patients with type 2 diabetes have cardiovascular disease}


death, was reduced by $34 \%$ (HR 0.66, 95\% CI 0.53-0.81, $P<.001$ ).

In addition, canagliflozin slowed the progression of chronic eGFR decline. ${ }^{39}$ SGLT2 inhibitors have been shown to induce an initial decline in eGFR but with subsequent return to baseline and then an overall preservation of eGFR over time. ${ }^{40}$

Of note, in the CREDENCE trial, patients whose eGFR was 30 to $44 \mathrm{~mL} / \mathrm{min} / 1.73 \mathrm{~m}^{2}$ still benefited from canagliflozin; the primary outcome was reduced by $25 \%$ in this subgroup (HR 0.75, 95\% CI 0.59-0.95), and the number needed to treat was 19 . Initially, canagliflozin was contraindicated in patients with eGFR less than $45 \mathrm{~mL} / \mathrm{min} / 1.73 \mathrm{~m}^{2}$. However, in January 2020, the 100-mg once-daily dose was approved for use in patients with eGFR 30 to $44 \mathrm{~mL} / \mathrm{min} / 1.73 \mathrm{~m}^{2}$ with urinary albumin excretion less than $300 \mathrm{mg} /$ day.

Canagliflozin is the only SGLT-2 inhibitor studied in a large trial with a primary renal outcome. The EMPA-REG OUTCOME and the DECLARE-TIMI 58 trials had prespecified secondary renal composite outcomes that showed favorable results for renal benefit, but it is prudent to note that the composite outcomes consisted of different criteria.

The EMPA-REG trial ${ }^{41}$ found a $39 \%$ reduction compared with placebo for the renal composite outcome of progression to macroalbuminuria, a doubling of serum creatinine level accompanied by an eGFR of $\leq 45 \mathrm{~mL} /$ $\min / 1.73 \mathrm{~m}^{2}$, initiation of renal replacement therapy, or death from renal disease.

The DECLARE-TIMI 58 trial $^{42}$ had a renal composite outcome consisting of sustained decrease in eGFR by at least $40 \%$ to less than $60 \mathrm{~mL} / \mathrm{min} / 1.73 \mathrm{~m}^{2}$, end-stage renal disease, and renal death; there was a $47 \%$ reduction compared with placebo.

The VERTIS-CV trial $^{24}$ had a renal composite outcome that included renal death, renal replacement therapy, or doubling of serum creatinine. A statistically significant renal benefit was not found, although ertugliflozin did show a trend for reducing the rate of eGFR decline over time, similar to the other 3 SGLT-2 inhibitors.

Meta-analysis. In the meta-analysis by Zelniker et $\mathrm{al}^{25}$ of the first 3 cardiovascular outcome trials (EMPA-REG OUTCOME, ${ }^{21}$
CANVAS, ${ }^{22}$ and DECLARE-TIMI $58^{23}$ ), the composite outcome of worsening renal function, end-stage renal disease, or renal death was reduced by $45 \%$, suggesting a renal protective benefit of SGLT-2 inhibitors as a class.

The American Diabetes Association ${ }^{43}$ currently recommends empagliflozin, canagliflozin, and dapagliflozin as second-line therapy after metformin in patients with type 2 diabetes and chronic kidney disease whose eGFR is at least $45 \mathrm{~mL} / \mathrm{min} / 1.73 \mathrm{~m}^{2}$ (except for canagliflozin $100 \mathrm{mg}$, which can be used if eGFR is at least $30 \mathrm{~mL} / \mathrm{min} / 1.73 \mathrm{~m}^{2}$ and urinary albumin excretion is more than $300 \mathrm{mg} /$ day).

The CVD REAL 3 study $^{44}$ (Comparative Effectiveness of Cardiovascular Outcomes in New Users of SGTT-2 Inhibitors) evaluated the renal outcomes of SGLT-2 inhibitors in real-world clinical practice settings around the world. The rate of eGFR decline was significantly less in the SGLT-2 inhibitor group than with other glucose-lowering drugs, and the composite outcome of a 50\% eGFR decline or end-stage renal disease was reduced by $51 \%$ (HR 0.49, 95\% CI 0.35-0.67). These results were consistent across countries and baseline eGFR.

\section{MECHANISM OF RENAL PROTECTION}

The mechanism by which SGLT-2 inhibitors protect the kidneys is also not fully understood and is probably multifactorial.

A proposed mechanism is correction of glomerular hyperfiltration, which is a risk factor for progression of diabetic nephropathy. ${ }^{45}$ SGLT-2 inhibitors inhibit uptake of glucose and sodium in the proximal tubule, leading to an increase in delivery of sodium to the distal tubule and juxtaglomerular apparatus. The juxtaglomerular apparatus perceives this increase in sodium as a decrease in glomerular perfusion, causing the afferent arteriole to vasoconstrict, which in turn attenuates the hyperfiltration. ${ }^{46}$

This afferent arteriolar constriction manifests as a transient reduction in eGFR of approximately 3 to $4 \mathrm{~mL} / \mathrm{min} / 1.73 \mathrm{~m}^{2}$ in the first few weeks of SGLT-2 therapy and a reduction in albuminuria. Renal function subsequently stabilizes, and ultimately the progression of renal disease is slower with SGLT-2 inhibitors 
than with placebo in the long term. This effect was seen in the cardiovascular outcome trials of all 4 SGLT-2 inhibitors ${ }^{39,41,42}$ as well as in the CVD REAL 3 study. ${ }^{44}$

An ongoing clinical trial is assessing the efficacy of empagliflozin in patients with chronic kidney disease. A trial evaluating dapagliflozin in patients with chronic kidney disease was recently terminated early due to the overwhelming benefit of dapagliflozin in this population. The results of this trial are of great interest, as they may further expand the utilization of this drug.

\section{EFFECT ON METABOLIC OUTCOMES}

SGLT-2 inhibitors have been shown to promote weight loss and lower blood pressure. Taking these drugs as monotherapy for 24 to 26 weeks, patients lost approximately 2.3 to $3.5 \mathrm{~kg}$. Systolic blood pressure decreased by 1.4 to $3.7 \mathrm{~mm} \mathrm{Hg}$, and diastolic blood pressure decreased by 0.6 to $2.0 \mathrm{~mm} \mathrm{Hg} .{ }^{5-8}$ Reductions in weight and blood pressure persist in patients with eGFR less than $60 \mathrm{~mL} / \mathrm{min} / 1.73$ $\mathrm{m}^{2}$ even when the glucose-lowering effect of SGLT-2 inhibitors is attenuated. ${ }^{47}$

SGLT-2 inhibitors have not been approved for use solely as weight-loss medications. However, when they are used in combination with other antiobesity medications they seem to have an additive effect on weight loss and blood pressure compared with SGLT-2 inhibitor monotherapy.

Hollander et $\mathrm{al}^{48}$ compared the effect of canagliflozin, phentermine, canagliflozin and phentermine combined ("can-phen"), and placebo in patients without type 2 diabetes. Patients lost an average of $0.6 \mathrm{~kg}$ on placebo, $1.9 \mathrm{~kg}$ on canagliflozin, $4.1 \mathrm{~kg}$ on phentermine, and $7.3 \mathrm{~kg}$ on can-phen over 26 weeks. Compared with placebo, can-phen produced a statistically significant weight loss of $6.9 \%$ ( $P$ $<.001)$. In addition, there was a statistically significant reduction in systolic blood pressure in the can-phen group compared with placebo (difference of $-4.2 \mathrm{~mm} \mathrm{Hg}, P=.015$ ).

Combination therapy with SGLT-2 inhibitors and GLP-1 receptor agonists has been studied in patients with type 2 diabetes, with the primary outcome of glycemic control and secondary outcomes including changes in weight and blood pressure.

A meta-analysis ${ }^{49}$ of 4 large, randomized controlled trials showed that patients who received combination therapy lost significantly more weight than those who received SGLT-2 inhibitor monotherapy (difference $=-1.61 \mathrm{~kg}$, $P=.01$ ), and they had significantly reduced systolic blood pressure (difference $=-3.32 \mathrm{~mm}$ $\mathrm{Hg}, \mathrm{P}<.001) .{ }^{49}$ Hemoglobin $\mathrm{A}_{1 \mathrm{c}}$ reduction was also greater in the combination therapy group compared with monotherapy (difference $=-0.74 \%, P<.001)$.

\section{STUDIES IN NONALCOHOLIC FATTY LIVER DISEASE (NAFLD)}

NAFLD is a chronic liver disease that can ultimately progress to liver cirrhosis, and there are no FDA-approved pharmacotherapies for it to date. Such treatments are needed, especially considering that the prevalence of NAFLD is high in the type 2 diabetes population.

Empagliflozin, dapagliflozin, and canagliflozin have been studied for their effect on NAFLD. Overall, they have been shown to decrease alanine aminotransferase and improve steatosis and fibrosis along with reducing hemoglobin $\mathrm{A}_{1 \mathrm{c}}$ and body weight. ${ }^{50}$ Further randomized controlled trials are needed to evaluate the benefit of SGLT-2 inhibitors in NAFLD in patients with and without diabetes.

The mechanism by which SGLT-2 inhibitors improve NAFLD remains unclear. A popular theory is that a chronic inflammatory state underlies type 2 diabetes and its complications, and patients with NAFLD show significant increases in inflammatory markers as well..$^{51}$ Therefore, it is speculated that SGLT-2 inhibitors have several features that can provide anti-inflammatory benefits to improve NAFLD. One feature is the reduction in weight as well as subcutaneous and visceral fat, ${ }^{52}$ as weight reduction is known to reduce inflammatory markers. ${ }^{53}$

In addition, SGLT-2 inhibitors decrease serum uric acid levels. ${ }^{21}$ Uric acid has been associated with oxidative stress and vascular injury in in-vitro and animal studies ${ }^{54}$ leading to the hypothesis that lowering of serum uric acid may improve the inflammatory state. Fralick et al ${ }^{55}$ showed that SGLT-2 inhibitors
To date, no treatments have been shown to lower mortality in heart failure with preserved ejection fraction 
decreased the rate of gout in patients with type 2 diabetes compared with those who were prescribed a GLP-1 receptor agonist.

Bottom line. SGLT-2 inhibitors should be considered in patients with type 2 diabetes who are also overweight or obese. They may also have an added benefit of improving NAFLD. In cases in which further hemoglobin $A_{1 c}$ reduction and weight loss is preferred, combination therapy with GLP-1 receptor agonists is a reasonable option. In those without type 2 diabetes, canagliflozin plus phentermine seems to have a synergistic effect in promoting significant weight loss. Subsequent studies evaluating the combination of other SGLT-2 inhibitors and phentermine and assessing the effect of this combination therapy in the type 2 diabetes population is of interest.

\section{ADVERSE EFFECTS OF SGLT-2 INHIBITORS}

Several adverse events related to the use of SGLT-2 inhibitors have been reported. Some are drug-specific and others are class-specific. $^{21-23}$

Fractures, amputations with canagliflozin. The hazard ratio for the risk of fractures with
Early diabetic kidney disease by 16 years shortens life canagliflozin was 1.26 (95\% CI 1.04-1.52), and the hazard ratio for the risk of amputations was 1.97 (95\% CI 1.41-2.75) in the CANVAS trial. ${ }^{22}$ However, the hazard ratios for these 2 events were not significant in the CREDENCE trial. ${ }^{39}$ Moreover, the increased risk for fractures and amputations has not been seen in randomized control trials of empagliflozin, dapagliflozin, and ertugliflozin. Thus, the FDA removed the boxed warning about the amputation risk with canagliflozin in August 2020.56

Genital infections. As a class, SGLT-2 inhibitors increase the risk of genital infections. ${ }^{8,21-23}$ Urinary tract infections were generally not significantly increased as a class, but an increase in female urinary tract infections was seen with empagliflozin. ${ }^{21}$

Fournier gangrene. In a postmarketing analysis based on the FDA adverse event reporting system and published case reports, SGLT-2 inhibitors as a class were associated with an increased risk of Fournier gangrene: 55 cases of Fournier gangrene were identified from March 2013 to January 2019: 21 cases were attributed to canagliflozin, 16 to dapa- gliflozin, and 18 to empagliflozin. ${ }^{57}$ This increased risk of Fournier gangrene has not been shown in any of the randomized clinical trials, but due to the severe and fatal nature of this infection, it is crucial to have a high index of suspicion for it in order to detect these cases in the early stages.

Diabetic ketoacidosis. SGLT-2 inhibitorassociated diabetic ketoacidosis may present atypically (ie, with a lower-than-expected glucose level) which can result in missed diagnoses and delays in treatment. ${ }^{58}$

A proposed mechanism of SGLT-2 inhibitor-associated diabetic ketoacidosis is that the increased urinary excretion of glucose suppresses insulin secretion by the beta cells which in turn decreases the antilipolytic activity of insulin. This stimulates production of free fatty acids that are then converted to ketone bodies. ${ }^{59}$ In addition, the decrease in insulin activity increases the activity of carnitine palmitoyl-transferase I (CPT-I) through inhibition of acetyl-CoA carboxylase. CPT-I promotes the transport of fatty acids into the mitochondria which ultimately increases ketone body production..$^{59}$ There is also evidence that SGLT-2 inhibitors increase glucagon secretion. As glucagon suppresses acetyl-CoA carboxylase, CPT-I activity is increased, leading to ketone body production. ${ }^{60}$

According to the American Association of Clinical Endocrinologists position statement on SGLT-2 inhibitors and diabetic ketoacidosis, this complication occurs infrequently, and the benefits of SGLT-2 inhibitors clearly outweigh the risk, so continued use of SGLT-2 inhibitors in type 2 diabetes is recommended. ${ }^{58}$ However, evidence is emerging that surgery may increase the risk of ketoacidosis in patients taking SGLT-2 inhibitors. ${ }^{61}$

In March 2020, the FDA approved a label change for all SGLT-2 inhibitors on the market, recommending temporary discontinuation of the drug before scheduled surgery. Empagliflozin, canagliflozin, and dapagliflozin should be discontinued 3 days before scheduled surgery and ertugliflozin should be discontinued 4 days before. The drug can be reinitiated after surgery when oral intake has returned to baseline. ${ }^{62}$

Benefit outweighs risk. SGLT-2 inhibitors have an abundance of additional benefits 


\section{TABLE 3}

\section{Risks and benefits of SGLT-2 inhibitors}

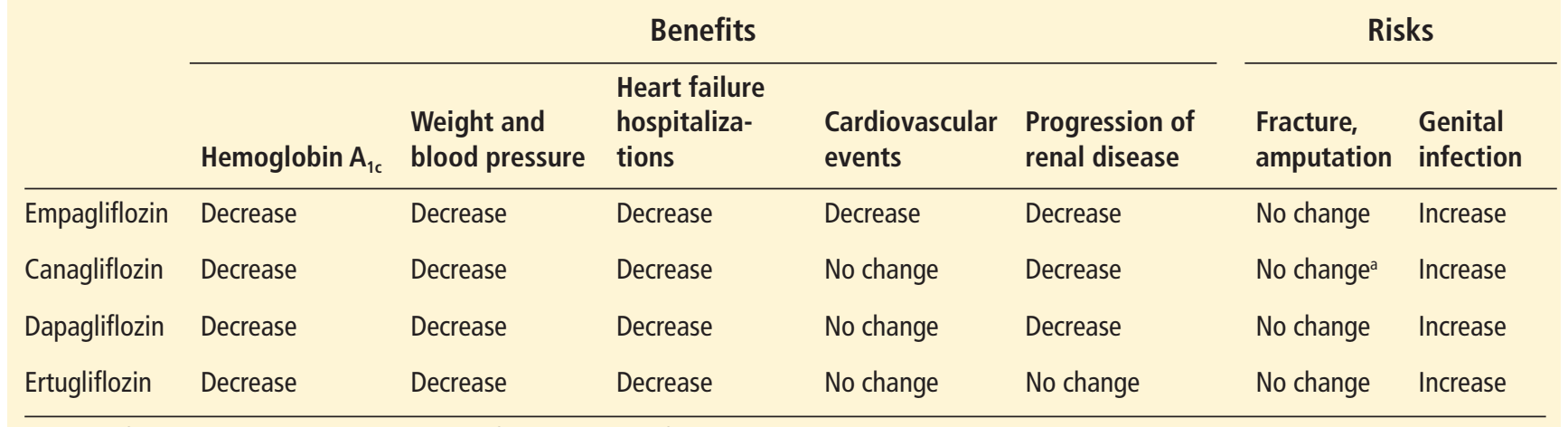

a Changed from "increases risk" to "no change" after the removal of the black box warning by the US Food and Drug Administration.

aside from improving glycemic control. Based on the safety data we have thus far, the riskbenefit ratio unquestionably favors the use of SGLT-2 inhibitors, and they should be recommended for any patient with type 2 diabetes who does not have any absolute contraindications (Table 3). Relative contraindications may include recurrent urinary tract or genital infections. For canagliflozin, risk factors for amputation such as prior history of amputation, peripheral vascular disease, neuropathy, and diabetic foot ulcers should be considered before initiation and then monitored for signs and symptoms of foot infections if initiated. Fournier gangrene is a severe and fatal infection; any patient on an SGLT-2 inhibitor should be counseled about the symptoms, and providers need to have heightened awareness of the possibility of Fournier gangrene in order to detect this condition early.

\section{REVIEW OF THE GUIDELINES}

In 2020, diabetes treatment algorithms were issued by the American Diabetes Association $^{43}$ and the American Association of Clinical Endocrinologists. ${ }^{63}$

\section{American Diabetes Association}

- In patients who have established ASCVD, high ASCVD risk (age $\geq 55$ with coronary, carotid, or lower extremity artery stenosis $>50 \%$, or left ventricular hypertrophy), heart failure, or chronic kidney disease, SGLT-2 inhibitors are considered for use as second-line therapy (first-line is met- formin) regardless of baseline hemoglobin $\mathrm{A}_{1 \mathrm{c}}$. The 3 SGLT-2 inhibitors with cardiovascular and renal benefits are empagliflozin, canagliflozin, and dapagliflozin.

- In patients whose hemoglobin $\mathrm{A}_{1 \mathrm{c}}$ is above their individual target and who do not have established ASCVD, high ASCVD risk, heart failure, or chronic kidney disease, SGLT-2 inhibitors are considered for use as second-line therapy.

\section{American Association}

\section{of Clinical Endocrinologists}

- In patients with established ASCVD, high ASCVD risk, or chronic kidney disease, SGLT-2 inhibitors and GLP-1 receptor agonists are recommended as first-line therapy independent of glycemic control.

- If entry hemoglobin $\mathrm{A}_{1 \mathrm{c}}$ is less than $7.5 \%$, monotherapy is recommended with metformin, a GLP-1 receptor agonist, or a SGLT-2 inhibitor (strength of the recommendation is equal).

- For those with stage 3 chronic kidney disease, canagliflozin is recommended.

- For those with heart failure with reduced ejection fraction, dapagliflozin is recommended.

- If entry hemoglobin $A_{1 c}$ is $7.5 \%$ to $9.0 \%$ or higher or if uncontrolled on monotherapy, dual therapy is recommended with SGLT-2 inhibitor and GLP-1 receptor agonists as the top choices in the hierarchy along with metformin. The 2 drug classes are also the top choices for triple therapy. 


\section{Bottom line}

SGLT-2 inhibitors are recommended for use as either first-line or second-line therapy regardless of baseline hemoglobin $A_{1 c}$ in patients who have established ASCVD, high ASCVD risk, chronic kidney disease, or heart failure. They are also recommended for use in those who would benefit from weight loss and in those whom prevention of hypoglycemia is a priority according to the ADA.

\section{FUTURE DIRECTIONS}

Use in type 1 diabetes? Currently, SGLT2 inhibitors as a class are not recommended for use in type 1 diabetes. Large, randomized, placebo-controlled studies have been undertaken with dapagliflozin, ${ }^{64}$ empagliflozin, ${ }^{65}$ and canagliflozin ${ }^{66}$ as adjunct therapy to insulin in patients with type 1 diabetes. Common results included reduction in hemoglobin $A_{1}$ and weight without increases in hypoglycemia events. However, the incidence of diabetic ketoacidosis was higher in the SGLT-2 inhibitor groups in all 3 studies. ${ }^{64-66}$ None of these drugs have been approved by the FDA for use in type 1 diabetes. Future studies involving type 1 diabetes and SGLT-2 inhibitors include adjunctive use with closed-loop insulin pumps and combination therapy with GLP-1 receptor agonists.

Sotagliflozin is an SGLT-1 and SGLT-2 dual inhibitor being studied for treatment of type 1 diabetes and type 2 diabetes. Besides the distal segment of the proximal tubule of the kidneys, SGLT-1 is also located in the proximal intestine, and inhibition results in reduced glucose absorption and delays postprandial hyperglycemia. In a phase 3 clinical trial, ${ }^{67}$ its efficacy and safety were tested as an add-on therapy to insulin in patients with type 1 diabetes. Although the drug was effective in improving glycemic control, the rate of diabetic ketoacidosis was higher compared with placebo. ${ }^{67}$ Sotagliflozin was rejected by the FDA as adjunct therapy for type 1 diabetes. There is currently an ongoing clinical trial studying the efficacy of sotagliflozin in type 2 diabetes.

\section{DISCLOSURES}

The authors report no relevant financial relationships which, in the context of their contributions, could be perceived as a potential conflict of interest.

\section{REFERENCES}

1. Neumiller JJ, White JR Jr, Campbell RK. Sodium-glucose co-transport inhibitors: progress and therapeutic potential in type 2 diabetes mellitus. Drugs 2010; 70(4):377-385. doi:10.2165/11318680-000000000-00000

2. Bakris GL, Fonseca VA, Sharma K, Wright EM. Renal sodium-glucose transport: role in diabetes mellitus and potential clinical implications. Kidney Int 2009; 75(12):1272-1277. doi:10.1038/ki.2009.87

3. Jabbour SA. SGLT2 inhibitors to control glycemia in type 2 diabetes mellitus: a new approach to an old problem. Postgrad Med 2014; 126(1):111-117. doi:10.3810/pgm.2014.01.2731

4. Nauck MA, Del Prato S, Meier JJ, et al. Dapagliflozin versus glipizide as add-on therapy in patients with type 2 diabetes who have inadequate glycemic control with metformin: a randomized, 52-week, double-blind, active-controlled noninferiority trial. Diabetes Care 2011; 34(9):2015-2022. doi:10.2337/dc11-0606

5. Stenlöf K, Cefalu WT, Kim KA, et al. Efficacy and safety of canagliflozin monotherapy in subjects with type 2 diabetes mellitus inadequately controlled with diet and exercise. Diabetes Obes Metab 2013; 15(4):372-382. doi:10.1111/dom.12054

6. Roden M, Weng J, Eilbracht J, et al. Empagliflozin monotherapy with sitagliptin as an active comparator in patients with type 2 diabetes: a randomised, double-blind, placebo-controlled, phase 3 trial. Lancet Diabetes Endocrinol 2013; 1(3):208-219. doi:10.1016/S2213-8587(13)70084-6

7. Ferrannini E, Ramos SJ, Salsali A, Tang W, List JF. Dapagliflozin monotherapy in type 2 diabetic patients with inadequate glycemic control by diet and exercise: a randomized, double-blind, placebocontrolled, phase 3 trial. Diabetes Care 2010; 33(10):2217-2224. doi:10.2337/dc10-0612

8. Aronson R, Frias J, Goldman A, Darekar A, Lauring B, Terra SG. Long-term efficacy and safety of ertugliflozin monotherapy in patients with inadequately controlled T2DM despite diet and exercise: VERTIS MONO extension study. Diabetes Obes Metab 2018; 20(6):1453-1460. doi:10.1111/dom.13251

9. Cefalu WT, Leiter LA, Yoon KH, et al. Efficacy and safety of canagliflozin versus glimepiride in patients with type 2 diabetes inadequately controlled with metformin (CANTATA-SU): 52 week results from a randomised, double-blind, phase 3 non-inferiority trial. Lancet 2013; 382(9896):941-950. doi:10.1016/S0140-6736(13)60683-2

10. Häring HU, Merker L, Seewaldt-Becker E, et al. Empagliflozin as add-on to metformin in patients with type 2 diabetes: a 24-week randomized, double-blind, placebo-controlled trial. Diabetes Care 2014; 37(6):1650-1659. doi:10.2337/dc13-2105

11. Rosenstock J, Frias J, Páll D, et al. Effect of ertugliflozin on glucose control, body weight, blood pressure and bone density in type 2 diabetes mellitus inadequately controlled on metformin monotherapy (VERTIS MET). Diabetes Obes Metab 2018; 20(3):520-529. doi:10.1111/dom.13103

12. Yale JF, Bakris G, Cariou B, et al. Efficacy and safety of canagliflozin in subjects with type 2 diabetes and chronic kidney disease. Diabetes Obes Metab 2013; 15(5):463-473. doi:10.1111/dom.12090

13. Wilding JP, Woo V, Soler NG, et al. Long-term efficacy of dapagliflozin in patients with type 2 diabetes mellitus receiving high doses of insulin: a randomized trial. Ann Intern Med 2012 156(6):405-415. doi:10.7326/0003-4819-156-6-201203200-00003

14. Rosenstock J, Jelaska A, Frappin G, et al. Improved glucose control with weight loss, lower insulin doses, and no increased hypoglycemia with empagliflozin added to titrated multiple daily injections of insulin in obese inadequately controlled type 2 diabetes. Diabetes Care 2014; 37(7):1815-1823. doi:10.2337/dc13-3055

15. Woo VC, Berard LD, Bajaj HS, Ekoé JM, Senior PA. Considerations for initiating a sodium-glucose co-transporter 2 inhibitor in adults with type 2 diabetes using insulin. Can J Diabetes 2018; 42(1):88-93. doi:10.1016/j.jcjd.2017.01.009 
16. Einarson TR, Acs A, Ludwig C, Panton UH. Prevalence of cardiovascular disease in type 2 diabetes: a systematic literature review of scientific evidence from across the world in 2007-2017. Cardiovasc Diabetol 2018; 17(1):83. doi:10.1186/s12933-018-0728-6

17. Kristensen SL, Preiss D, Jhund PS, et al. Risk related to pre-diabetes mellitus and diabetes mellitus in heart failure with reduced ejection fraction: insights from prospective comparison of ARNI with ACEI to determine impact on global mortality and morbidity in heart failure trial. Circ Heart Fail 2016; 9(1):e002560. doi:10.1161/CIRCHEARTFAILURE.115.002560

18. Kristensen SL, Mogensen UM, Jhund PS, et al. Clinical and echocardiographic characteristics and cardiovascular outcomes according to diabetes status in patients with heart failure and preserved ejection fraction: a report from the I-Preserve Trial (Irbesartan in Heart Failure With Preserved Ejection Fraction). Circulation 2017; 135(8):724-735. doi:10.1161/CIRCULATIONAHA.116.024593

19. Bertoni AG, Hundley WG, Massing MW, Bonds DE, Burke GL, Goff DC Jr. Heart failure prevalence, incidence, and mortality in the elderly with diabetes. Diabetes Care 2004; 27(3):699-703. doi:10.2337/diacare.27.3.699

20. Vaur L, Gueret P, Lievre M, Chabaud S, Passa P; DIABHYCAR Study Group (type 2 DIABetes, Hypertension, CARdiovascular Events and Ramipril) study. Development of congestive heart failure in type 2 diabetic patients with microalbuminuria or proteinuria: observations from the DIABHYCAR (type 2 DIABetes, Hypertension, CArdiovascular Events and Ramipril) study. Diabetes Care 2003; 26(3):855-860. doi:10.2337/diacare.26.3.855

21. Zinman B, Wanner C, Lachin JM, et al. Empagliflozin, cardiovascular outcomes, and mortality in type 2 diabetes. N Engl J Med 2015; 373(22):2117-2128. doi:10.1056/NEJMoa1504720

22. Neal B, Perkovic V, Mahaffey KW, et al. Canagliflozin and cardiovascular and renal events in type 2 diabetes. N Engl J Med 2017; 377(7):644-657. doi:10.1056/NEJMoa1611925

23. Wiviott SD, Raz I, Bonaca MP, et al. Dapagliflozin and cardiovascular outcomes in type 2 diabetes. N Engl J Med 2019; 380(4):347-357. doi:10.1056/NEJMoa1812389

24. Cannon CP, Pratley R, Dagogo-Jack S, et al. Cardiovascular outcomes with ertugliflozin in type 2 diabetes. N Engl J Med 2020; 383(15):1425-1435. doi:10.1056/NEJMoa2004967

25. Zelniker TA, Wiviott SD, Raz I, et al. SGLT2 inhibitors for primary and secondary prevention of cardiovascular and renal outcomes in type 2 diabetes: a systematic review and meta-analysis of cardiovascular outcome trials. Lancet 2019; 393(10166):31-39. doi:10.1016/S0140-6736(18)32590-X

26. Kato ET, Silverman MG, Mosenzon O, et al. Effect of dapagliflozin on heart failure and mortality in type 2 diabetes mellitus. Circulation 2019; 139(22):2528-2536. doi:10.1161/CIRCULATIONAHA.119.040130

27. Yancy CW, Jessup M, Bozkurt B, et al. 2013 ACCF/AHA guideline for the management of heart failure: executive summary: a report of the American College of Cardiology Foundation/American Heart Association Task Force on practice guidelines. Circulation 2013; 128(16):1810-1852. doi:10.1161/CIR.0b013e31829e8807

28. McMurray JJV, Solomon SD, Inzucchi SE, et al. Dapagliflozin in patients with heart failure and reduced ejection fraction. N Engl J Med 2019; 381(21):1995-2008. doi:10.1056/NEJMoa1911303

29. US Food and Drug Administration (FDA). FDA approves new treatment for a type of heart failure. www.fda.gov/news-events/pressannouncements/fda-approves-new-treatment-type-heart-failure. Accessed December 1, 2020.

30. Packer M, Anker SD, Butler J, et al. Cardiovascular and renal outcomes with empagliflozin in heart failure. N Engl J Med 2020; 383(15):1413-1424. doi:10.1056/NEJMoa2022190

31. Kosiborod M, Lam CSP, Kohsaka S, et al. Cardiovascular events associated with SGLT-2 inhibitors versus other glucose-lowering drugs: the CVD-REAL 2 study. J Am Coll Cardiol 2018; 71(23):2628-2639. doi:10.1016/j.jacc.2018.03.009

32. Baartscheer A, Schumacher CA, Wüst RC, et al. Empagliflozin decreases myocardial cytoplasmic $\mathrm{Na}+$ through inhibition of the cardiac $\mathrm{Na}+/ \mathrm{H}+$ exchanger in rats and rabbits. Diabetologia 2017; 60(3):568-573. doi:10.1007/s00125-016-4134-x

33. Uthman L, Baartscheer A, Bleijlevens B, et al. Class effects of SGLT2 inhibitors in mouse cardiomyocytes and hearts: inhibition of $\mathrm{Na}+\mathrm{H}+$ exchanger, lowering of cytosolic $\mathrm{Na}+$ and vasodilation. Diabetologia 2018; 61(3):722-726. doi:10.1007/s00125-017-4509-7

34. Baartscheer A, Hardziyenka M, Schumacher CA, et al. Chronic inhibition of the $\mathrm{Na}+/ \mathrm{H}+-$ exchanger causes regression of hypertrophy, heart failure, and ionic and electrophysiological remodelling. $\mathrm{Br} \mathrm{J}$ Pharmacol 2008; 154(6):1266-1275. doi:10.1038/bjp.2008.189

35. Kang S, Verma S, Teng G, et al. Direct effects of empagliflozin on extracellular matrix remodeling in human cardiac fibroblasts: novel translational clues to EMPA-REG outcome. Can J Cardiol 2017; 33(10):S169. doi:10.1016/j.cjca.2017.07.330

36. USRDS. ESRD quarterly update. www.usrds.org/esrd-quarterlyupdate. Accessed December 2, 2020.

37. Naylor KL, Kim SJ, McArthur E, Garg AX, McCallum MK, Knoll GA. Mortality in incident maintenance dialysis patients versus incident solid organ cancer patients: a population-based cohort. Am J Kidney Dis 2019; 73(6):765-776. doi:10.1053/j.ajkd.2018.12.011

38. Wen CP, Chang CH, Tsai MK, et al. Diabetes with early kidney involvement may shorten life expectancy by 16 years. Kidney Int 2017; 92(2):388-396. doi:10.1016/j.kint.2017.01.030

39. Perkovic V, Jardine MJ, Neal B, et al. Canagliflozin and renal outcomes in type 2 diabetes and nephropathy. N Engl J Med 2019; 380(24):2295-2306. doi:10.1056/NEJMoa1811744

40. Nespoux J, Vallon V. SGLT2 inhibition and kidney protection. Clin Sci (Lond) 2018; 132(12):1329-1339. doi:10.1042/CS20171298

41. Wanner Ch, Inzucchi SE, Zinman B. Empagliflozin and progression of kidney disease in type 2 diabetes. N Engl J Med 2016; 375(18):18011802. doi:10.1056/NEJMc1611290

42. Mosenzon O, Wiviott SD, Cahn A, et al. Effects of dapagliflozin on development and progression of kidney disease in patients with type 2 diabetes: an analysis from the DECLARE-TIMI 58 randomised trial. Lancet Diabetes Endocrinol 2019; 7(8):606-617. doi:10.1016/S2213-8587(19)30180-9

43. American Diabetes Association. 9. Pharmacologic approaches to glycemic treatment: standards of medical care in diabetes-2020. Diabetes Care 2020; 43(suppl 1):S98-S110. doi:10.2337/dc20-S009

44. Heerspink HJL, Karasik A, Thuresson M, et al. Kidney outcomes associated with use of SGLT2 inhibitors in real-world clinical practice (CVDREAL 3): a multinational observational cohort study. Lancet Diabetes Endocrinol 2020; 8(1):27-35. doi:10.1016/\$2213-8587(19)30384-5

45. Ruggenenti P, Porrini EL, Gaspari F, et al. Glomerular hyperfiltration and renal disease progression in type 2 diabetes. Diabetes Care 2012; 35(10):2061-2068. doi:10.2337/dc11-2189

46. Heerspink HJ, Perkins BA, Fitchett DH, Husain M, Cherney DZ. Sodium glucose cotransporter 2 inhibitors in the treatment of diabetes mellitus: cardiovascular and kidney effects, potential mechanisms, and clinical applications. Circulation 2016; 134(10):752-772. doi:10.1161/CIRCULATIONAHA.116.021887

47. Cherney DZI, Cooper ME, Tikkanen I, et al. Pooled analysis of phase III trials indicate contrasting influences of renal function on blood pressure, body weight, and $\mathrm{HbA} 1 \mathrm{c}$ reductions with empagliflozin. Kidney Int 2018; 93(1):231-244. doi:10.1016/j.kint.2017.06.017

48. Hollander P, Bays HE, Rosenstock J, et al. Coadministration of canagliflozin and phentermine for weight management in overweight and obese individuals without diabetes: a randomized clinical trial. Diabetes Care 2017; 40(5):632-639. doi:10.2337/dc16-2427

49. Castellana M, Cignarelli A, Brescia F, et al. Efficacy and safety of GLP-1 receptor agonists as add-on to SGLT2 inhibitors in type 2 diabetes mellitus: a meta-analysis. Sci Rep 2019; 9(1):19351. doi:10.1038/s41598-019-55524-w

50. Ranjbar G, Mikhailidis DP, Sahebkar A. Effects of newer antidiabetic drugs on nonalcoholic fatty liver and steatohepatitis: think out of the box!. Metabolism 2019; 101:154001. doi:10.1016/j.metabol.2019.154001

51. Genc H, Dogru T, Kara M, et al. Association of plasma visfatin with hepatic and systemic inflammation in nonalcoholic fatty liver disease. Ann Hepatol 2013; 12(4):548-555. pmid:23813132 
52. Bolinder J, Ljunggren Ö, Kullberg J, et al. Effects of dapagliflozin on body weight, total fat mass, and regional adipose tissue distribution in patients with type 2 diabetes mellitus with inadequate glycemic control on metformin. J Clin Endocrinol Metab 2012; 97(3):10201031. doi:10.1210/jc.2011-2260

53. Möller K, Ostermann Al, Rund K, et al. Influence of weight reduction on blood levels of C-reactive protein, tumor necrosis factor- $\alpha$, interleukin-6, and oxylipins in obese subjects. Prostaglandins Leukot Essent Fatty Acids 2016; 106:39-49. doi:10.1016/j.plefa.2015.12.001

54. Kushiyama A, Tanaka K, Hara S, Kawazu S. Linking uric acid metabolism to diabetic complications. World J Diabetes 2014; 5(6):787-795. doi:10.4239/wjd.v5.i6.787

55. Fralick M, Chen SK, Patorno E, Kim SC. Assessing the risk for gout with sodium-glucose cotransporter-2 inhibitors in patients with type 2 diabetes: a population-based cohort study. Ann Intern Med 2020; 172(3):186-194. doi:10.7326/M19-2610

56. US Food and Drug Administration (FDA). FDA removes boxed warning about risk of leg and foot amputations for the diabetes medicine canagliflozin (Invokana, Invokamet, Invokamet XR). www. fda.gov/drugs/drug-safety-and-availability/fda-removes-boxedwarning-about-risk-leg-and-foot-amputations-diabetes-medicinecanagliflozin. Accessed December 2, 2020.

57. Bersoff-Matcha SJ, Chamberlain C, Cao C, Kortepeter C, Chong WH. Fournier gangrene associated with sodium-glucose cotransporter-2 inhibitors: a review of spontaneous postmarketing cases. Ann Intern Med 2019; 170(11):764-769. doi:10.7326/M19-0085

58. Handelsman Y, Henry RR, Bloomgarden ZT, et al. American Association of Clinical Endocrinologists and American College of Endocrinology Position Statement on the association of SGLT-2 INHIBITORS and diabetic ketoacidosis. Endocr Pract 2016; 22(6):753-762. doi:10.4158/EP161292.PS

59. Ogawa W, Sakaguchi K. Euglycemic diabetic ketoacidosis induced by SGLT2 inhibitors: possible mechanism and contributing factors. J Diabetes Investig 2016; 7(2):135-138. doi:10.1111/jdi.12401
60. Kibbey RG. SGLT-2 inhibition and glucagon: Cause for alarm? Trends Endocrinol Metab 2015; 26(7):337-338. doi:10.1016/j.tem.2015.05.011

61. Thiruvenkatarajan V, Meyer EJ, Nanjappa N, Van Wijk RM, Jesudason D. Perioperative diabetic ketoacidosis associated with sodiumglucose co-transporter-2 inhibitors: a systematic review. Br J Anaesth 2019; 123(1):27-36. doi:10.1016/j.bja.2019.03.028

62. Drug Topics. FDA approves label changes to SGLT2 inhibitors. https:// www.drugtopics.com/view/fda-approves-safety-labeling-changessglt2-inhibitors. Accessed November 2, 2020.

63. Garber AJ, Handelsman Y, Grunberger G, et al. Consensus Statement by the American Association of Clinical Endocrinologists and American College of Endocrinology on the comprehensive type 2 diabetes management algorithm-2020 Executive Summary. Endocr Pract 2020; 26(1):107-139. doi:10.4158/CS-2019-0472

64. Dandona P, Mathieu C, Phillip M, et al. Efficacy and safety of dapagliflozin in patients with inadequately controlled type 1 diabetes: the DEPICT-1 52-week study. Diabetes Care 2018; 41(12):2552-2559. doi:10.2337/dc18-1087

65. Rosenstock J, Marquard J, Laffel LM, et al. Empagliflozin as adjunctive to insulin therapy in type 1 diabetes: the EASE Trials. Diabetes Care 2018; 41(12):2560-2569. doi:10.2337/dc18-1749

66. Henry RR, Thakkar P, Tong C, Polidori D, Alba M. Efficacy and safety of canagliflozin, a sodium-glucose cotransporter 2 inhibitor, as addon to insulin in patients with type 1 diabetes. Diabetes Care 2015; 38(12):2258-2265. doi:10.2337/dc15-1730

67. Garg SK, Henry RR, Banks P, et al. Effects of sotagliflozin added to insulin in patients with type 1 diabetes. N Engl J Med 2017; 377(24):2337-2348. doi:10.1056/NEJMoa1708337

Address: Vinni Makin, MBBS, MD, FACE, Department of Endocrinology Diabetes, and Metabolism, F20, Cleveland Clinic, 9500 Euclid Avenue,

Cleveland, OH 44195; makinv@ccf.org 


\section{SGLT-2 inhibitors for type 2 diabetes}

In the January 2021 issue, in Tsushima Y, Lansang MC, Makin V. The role of SGLT-2 inhibitors in managing type 2 diabetes. Cleve Clin J Med 2021; 88(1):4758. doi:10.3949/ccjm.88a.20088, a sentence on page 52 con-tained an error: "However, in January 2020, the 100-mg once-daily dose was approved for use in patients with eGFR 30 to $44 \mathrm{~mL} /$ $\min / 1.73 \mathrm{~m}^{2}$ with urinary albumin excretion less than $300 \mathrm{mg} /$ day." The 100-mg once-daily dose was approved for use in patients with eGFR 30 to $44 \mathrm{~mL} / \mathrm{min} / 1.73$ $\mathrm{m}^{2}$ with urinary albumin excretion more than $300 \mathrm{mg} /$ day. This has been corrected online. 